\title{
Screening of Phytochemical Components of Leaf Extracts
}

\author{
Sunita Kale* \\ All India Co-ordinated Research Project, Clothing and Textiles, Vasantrao Naik Marathwada \\ Krishi Vidyapeeth, Parbhani, 431402, Maharashtra, India \\ *Corresponding author
}

\section{A B S T R A C T}

\section{Keywords}

Phytochemicals, Leaf extract, TPC, Ethanol, Distilled water

\section{Article Info}

Accepted:

17 August 2020

Available Online:

10 September 2020
Phytochemicals are chemicals of plant origin, produced through primary or secondary metabolism of plants. Phytochemicals have become of great interest owing to their diverse applications. In the study five plant sources available locally and abundantly were selected to screen phytochemicals available in their leaves for testing their anti-microbial property for textiles. Leaf extracts were prepared using $70 \%$ ethanol and distilled water. The extracts were assessed for the presence of various classes of phytochemicals by applying standard tests and also total phenolic content of each extract was estimated. Results revealed that all the extracts contained tannins and phenolic compounds significantly. Flavonoids were poorly present in Amla leaf extract and significantly in Babul leaf extract. Alkaloids and saponin were poorly present in all extracts except moderate presence in Amlaleaf extract. Terpenoids were totally absent in all except Babul leaf extract. Ethanol extract of Amla leaf extract exhibited the highest Total Phenolic Content i.e. $156.79 \mathrm{mg} / \mathrm{g}$ of dry material followed by Babul leaf extract $117.99 \mathrm{mg} / \mathrm{g}$. Among distilled water extracts Babul leaf extract exhibited highest i.e. $106.05 \mathrm{mg} / \mathrm{g}$ followed by Amla leaf extract i.e. $100.27 \mathrm{mg} / \mathrm{g}$.

\section{Introduction}

India is well known all over the world for its ayurvedic treatment since prehistoric time. A wide range of medicinal plant parts like root, stem, flower, fruit, twigs exudates and modified plant organs have been used for extraction of raw drugs Chandra M.(2013), Manikandan et al., (2016). The medicinal value of these plants lies in some chemical substances that produce a definite physiological action on the human body Selvakumar Sivagnanam et al., (2016). These chemicals are termed as phytochemicals. Phytochemicals are chemicals of plant origin, produced by plants through primary or secondary metabolism. They generally have biological activity in the plant host and play an important role in plant growth. They are naturally present in the plants to defend themselves against various pathogenic microbes by showing the antimicrobial activity by inhibiting or killing microbes. Medicinal plants are richest bio-resource of drugs in traditional system of medicine and it also responsible for different colours, flavors 
and smell of plant Pradeep et al., (2014). Phytochemicals have recently become great interest owing to their versatile application Pushpa Ruwali et al., (2019), Saranraj et al., (2016). Phytochemicals play an important role in various preparations like food, cosmetics, pharmaceutical, flavours and agrochemical etc. as antimicrobial agents as well as antioxidants. Phytochemical screening is very important in identifying new sources of therapeutically and industrially important compounds like Alkaloids, Flavanoids, Phenolic Compounds, Saponins, Steroids, Tannins, Terpenoids etc. Akindele et al., (2007). They confer plants with odour (terpenoids), pigmentation (tannins and quinines), and flavor (capsacin) Mallikharjuna et al., (2007). They are a part of plant naturally defense system. These bioactive components are said to be responsible for the antimicrobial effects of plant extracts in vitro Ankita Sood et al., (2012). The mode of action of plants producing antimicrobial effects on selected textile materials can be better investigated if the active ingredients are identified and characterized Vastrad et al., (2016). There is worldwide realization that any plant known for a particular bio-efficacy should be explored. Muhammad Gulfraz et al., (2011). All the plant sources selected for the study were available locally and in abundant. The leaves of the plants were used for procuring the extract for testing the presence of phytochemical compounds.

\section{Materials and Methods}

Information about the plants selected for the study

\begin{tabular}{|c|l|l|l|l|}
\hline S. No & Name of the plant source & \multicolumn{1}{|c|}{ Botanical name } & \multicolumn{1}{|c|}{ Family } & \multicolumn{1}{c|}{ Part used } \\
\hline $\mathbf{1}$ & Amla & Phyllanthus emblica & Phyllanthaceae & Leaves \\
\hline $\mathbf{2}$ & Periwinkle & Catharanthus roseus & Apocynaceae & Leaves \\
\hline $\mathbf{3}$ & Lemon & Citrus limon & Rutaceae & Leaves \\
\hline $\mathbf{4}$ & Acacia & Vachellia nilotica & Fabaceae & Leaves \\
\hline $\mathbf{5}$ & Drumstick & Moringa oleifera & Moringacea & Leaves \\
\hline
\end{tabular}

\section{Processing of plant sources}

The leaves of the plants i.e. Amla, Periwinkle, Lemon, Babul and Drumstick were collected from the plants grown in the campus of the Vasantrao Naik Marathwada Krishi Vidyapeeth, Parbhani. The leaves were then washed thoroughly in distilled water and dried on a cloth to drain out excess water. Further drying of the leaves was done in the shade. The dried leaves were then ground into fine powder. Powder was then sieved through the sieve with mesh no. 150 to separate the unwanted residue and to get fine powder.

\section{Extract preparation}

Soaked $30 \mathrm{gm}$ of the plant source powder in $60 \mathrm{~mL}$ distilled water and in 70:30, Ethanol: distilled water mixture for 24 hours at room temperature. Centrifuged on 5000 RPM and filtered the supernatants. The residue was subsequently mixed with $25 \mathrm{~mL}$ of respective solvent and the process repeated for next 24 hours. The final extract obtained was filtered through Whatman filter paper.

\section{Phytochemical analysis}

Qualitative phytochemical screening was done for the identification of various classes of phenolic constituents, i.e. alkaloids, flavonoids, terpenoids, saponins etc. Different chemical tests performed for detecting these phenolic groups. The qualitative results are expressed as phytochemicals were $(+++)$ for significantly present, (++) for moderately present, (+) for poorly present, (-) for absent. 


\section{Test for Tannins and Phenolic compounds}

(a) Ferric chloride test: One $\mathrm{mL}$ of extract was separately stirred with $10 \mathrm{~mL}$ of distilled water and then filtered. A few drops of 5\% $\mathrm{FeCl}_{3}$ were added to the filtrate. Blue-black or blue-green colouration or precipitation was taken as an indication of the presence of tannins.

(b) Lead acetate test: Three $\mathrm{mL}$ of $10 \%$ lead acetate solution was added to $1 \mathrm{~mL}$ of extract. Appearance of bulky white precipitate confirmed the presence of phenolic compounds.

\section{Test for Flavonoids}

(a) Ammonia test: $\mathrm{A}$ few drops of $1 \% \mathrm{NH}_{3}$ solution was added to $1 \mathrm{~mL}$ of the extract in a test tube. A yellow coloration was observed for the presence of flavonoids.

(b) Sodium hydroxide test: Few drops of $20 \%$ $\mathrm{NaOH}$ solution was added to $1 \mathrm{~mL}$ of extract. On addition of $\mathrm{HCl}$, the changed yellow colour of the extract turned to a colourless solution that depicted the presence of flavonoids.

\section{Test for alkaloids}

(a) Dragendorff test: To $1 \mathrm{~mL}$ of extract, few drops of Dragendorff's reagent were added. A prominent yellow precipitate indicated presences of alkaloids.

(b) Wagner test: Few drops of Wagner's reagent were added by the side of test tube to $1 \mathrm{~mL}$ of extract. A reddish-brown precipitate confirmed the test as positive.

\section{Test for saponins}

Foam test: About $1 \mathrm{~mL}$ of the extract was boiled in $20 \mathrm{~mL}$ of distilled water in a water bath and filtered, $10 \mathrm{~mL}$ of the filtrate was mixed with the $5 \mathrm{~mL}$ of distilled water and mixed vigorously for $15 \mathrm{~min}$ to form a stable persistent froth. The presence of froth after 5 min was taken as an indication of presence of saponins.

\section{Test for Terpenoid}

Salkowski test: One $\mathrm{mL}$ of each extract was mixed with $0.5 \mathrm{~mL}$ of chloroform and $1 \mathrm{~mL}$ of concentrated $\mathrm{H}_{2} \mathrm{SO}_{4}$ was carefully added to form a layer. A reddish brown colouration of the interface formed showed positive results for the presence of terpenoids.

\section{Estimation of Total Phenolic Content (TPC)}

Total Phenolic Content was determined using the Folin-Ciocalteu Assay method (Singleton and Rossi 1965) using Gallic acid as the reference standard. To one $\mathrm{mL}$ of solvent extract $100 \mu \mathrm{L}$ of Folin-Ciocalteu reagent, was added and incubated at room temperature for 3 minutes then added $2 \mathrm{~mL}$ of $10 \% \mathrm{Na}_{2} \mathrm{CO}_{3}$ solution to the mixture.

The resulting solution was incubated for 90 minutes at room temperature under dark conditions, the absorbance was measured at $765 \mathrm{~nm}$ using the UV-Visible Spectrophotometer. Total Phenolic Content is expressed as gallic acid equivalent (GAE) in milligrams per gram of sample.

\section{Results and Discussion}

Table 1 showed presence of phytochemicals in Amla (Phyllanthus emblica) leaf extract. Amla (Phyllanthus emblica) leaf extracts in ethanol as well as in distilled water showed tannins and phenolic compounds significantly, flavonoids poorly, alkaloids and saponins moderately while terpenoids were absent 
Table.1 Phytochemical screening of Amla (Phyllanthus emblica) leaf extract

\begin{tabular}{|c|c|c|c|}
\hline \multirow[t]{2}{*}{ S.No } & \multirow[t]{2}{*}{ Phytochemical tests } & \multicolumn{2}{|c|}{ Solvents } \\
\hline & & Distilled water & Ethanol \\
\hline 1 & \multicolumn{3}{|c|}{ Test for tannins and phenolic compounds } \\
\hline $\mathbf{a}$ & Ferric chloride test & +++ & +++ \\
\hline b & Lead acetate test & +++ & +++ \\
\hline 2 & \multicolumn{3}{|l|}{ Test for flavonoids } \\
\hline $\mathbf{a}$ & Ammonia test & + & + \\
\hline $\mathbf{b}$ & Sodium hydroxide test & + & + \\
\hline 3 & \multicolumn{3}{|l|}{ Test for alkaloids } \\
\hline $\mathbf{a}$ & Dragendorff test & + & + \\
\hline b & Wagner test & ++ & ++ \\
\hline 4 & \multicolumn{3}{|l|}{ Test for saponins } \\
\hline $\mathbf{a}$ & Foam test & ++ & ++ \\
\hline 5 & \multicolumn{3}{|l|}{ Test for terpenoids } \\
\hline $\mathbf{a}$ & Salkowski test & - & - \\
\hline
\end{tabular}

$+++=$ Significantly present $++=$ moderately present $+=$ Poorly present $-=$ Absent

Table.2 Phyto- chemical screening of Lemon (Citrus lemon) leaf extract

\begin{tabular}{|c|c|c|c|}
\hline \multirow[t]{2}{*}{ S.No } & \multirow[t]{2}{*}{ Phytochemical test } & \multicolumn{2}{|l|}{ Solvents } \\
\hline & & Distilled water & Ethanol \\
\hline 1 & \multicolumn{3}{|c|}{ Test for tannins and phenolic compounds } \\
\hline $\mathbf{a}$ & Ferric chloride test & + & - \\
\hline $\mathbf{b}$ & Lead acetate test $\mathrm{k}$ & +++ & +++ \\
\hline 2 & \multicolumn{3}{|l|}{ Test for flavonoids } \\
\hline $\mathbf{a}$ & Ammonia test & - & - \\
\hline b & Sodium hydroxide test & - & - \\
\hline 3 & \multicolumn{3}{|l|}{ Test for alkaloids } \\
\hline $\mathbf{a}$ & Dragendorff test & + & + \\
\hline $\mathbf{b}$ & Wagner test & + & + \\
\hline 4 & \multicolumn{3}{|l|}{ Test for saponins } \\
\hline $\mathbf{a}$ & Foam test & + & + \\
\hline 5 & \multicolumn{3}{|l|}{ Test for terpenoids } \\
\hline $\mathbf{a}$ & Salkowski test & - & - \\
\hline
\end{tabular}


Table.3 Phytochemical screening of drumstick (Moringaoleifera) leaf extract

\begin{tabular}{|c|c|c|c|}
\hline \multirow[t]{2}{*}{ S no } & \multirow[t]{2}{*}{ Phytochemical tests } & \multicolumn{2}{|c|}{ Solvents } \\
\hline & & Distilled water & Ethanol \\
\hline 1 & \multicolumn{3}{|c|}{ Test for tannins and phenolic compounds } \\
\hline $\mathbf{a}$ & Ferric chloride test & + & + \\
\hline $\mathbf{b}$ & Lead acetate test & - & - \\
\hline 2 & \multicolumn{3}{|l|}{ Test for flavonoids } \\
\hline $\mathbf{a}$ & Ammonia test & - & - \\
\hline $\mathbf{b}$ & Sodium hydroxide test & - & - \\
\hline 3 & \multicolumn{3}{|l|}{ Test for alkaloids } \\
\hline $\mathbf{a}$ & Dragendorff test & + & + \\
\hline $\mathbf{b}$ & Wagner test & - & - \\
\hline 4 & \multicolumn{3}{|l|}{ Test for saponins } \\
\hline $\mathbf{a}$ & Foam test & + & + \\
\hline 5 & \multicolumn{3}{|l|}{ Test for terpenoids } \\
\hline $\mathbf{a}$ & Salkowski test & - & - \\
\hline
\end{tabular}

$+=$ Poorly present $-=$ Absent

Table.4 Phytochemical screening of babul (Acacia nilotica) leaf extract

\begin{tabular}{|c|c|c|c|}
\hline \multirow[t]{2}{*}{ S. no. } & \multirow[t]{2}{*}{ Phyto- chemical tests } & \multicolumn{2}{|c|}{ Solvents } \\
\hline & & Distilled water & Ethanol \\
\hline 1 & \multicolumn{3}{|c|}{ Test for tannins and phenolic compounds } \\
\hline $\mathbf{a}$ & Ferric chloride test & +++ & ++ \\
\hline b & Lead acetate test & +++ & +++ \\
\hline 2 & \multicolumn{3}{|l|}{ Test for flavonoids } \\
\hline $\mathbf{a}$ & Ammonia test & +++ & + \\
\hline b & Sodium hydroxide test & - & - \\
\hline 3 & \multicolumn{3}{|l|}{ Test for alkaloids } \\
\hline $\mathbf{a}$ & Dragendorff test & + & - \\
\hline $\mathbf{b}$ & Wagner test & + & - \\
\hline 4 & \multicolumn{3}{|l|}{ Test for saponins } \\
\hline $\mathbf{a}$ & Foam test & - & - \\
\hline 5 & \multicolumn{3}{|l|}{ Test for terpenoids } \\
\hline $\mathbf{a}$ & Salkowski test & + & + \\
\hline
\end{tabular}


Table.5 Phytochemical screening of Periwinkle (Catharanthus roseus) leaf extract

\begin{tabular}{|c|c|c|c|}
\hline \multirow[t]{2}{*}{ S no } & \multirow[t]{2}{*}{ Phytochimical test } & \multicolumn{2}{|c|}{ Solvents } \\
\hline & & Distilled water & Ethanol \\
\hline 1 & \multicolumn{3}{|c|}{ Test for tannins and phenolic compounds } \\
\hline $\mathbf{a}$ & Ferric chloride test & ++ & - \\
\hline b & Lead acetate test & +++ & +++ \\
\hline 2 & \multicolumn{3}{|l|}{ Test for flavonoids } \\
\hline $\mathbf{a}$ & Ammonia test & - & - \\
\hline b & Sodium hydroxide test & - & - \\
\hline 3 & \multicolumn{3}{|l|}{ Test for alkaloids } \\
\hline $\mathbf{a}$ & Dragendorff test & + & + \\
\hline b & Wagner test & + & + \\
\hline 4 & \multicolumn{3}{|l|}{ Test for saponins } \\
\hline $\mathbf{a}$ & Foam test & + & + \\
\hline 5 & \multicolumn{3}{|l|}{ Test for terpenoids } \\
\hline $\mathbf{a}$ & Salkowski test & + & + \\
\hline
\end{tabular}

Table.6 Total phenolic content of leaf extracts

\begin{tabular}{|c|l|c|c|}
\hline Sl. No. & Plant source & \multicolumn{2}{|c|}{ TPC (mg/g of dry material) } \\
\cline { 3 - 4 } & & Distilled water & Ethanol \\
\hline $\mathbf{1}$ & Lemon & 19.75 & 41.82 \\
\hline $\mathbf{3}$ & Drumstick & 27.29 & 55.47 \\
\hline $\mathbf{4}$ & Periwinkle & 18.93 & 33.85 \\
\hline $\mathbf{5}$ & Babul & 106.05 & 117.99 \\
\hline $\mathbf{6}$ & Amla & 100.27 & 156.79 \\
\hline
\end{tabular}

Table 2 exhibits presence of phyto-chemicals in Lemon (Citrus lemon) leaf extract. Lemon (Citrus lemon) leaf extracts in ethanol as well as distilled water contained tannins and phenolic compounds significantly, alkonoids and saponins poorly while, flavonoids and terpenoids were absent.

Table 3 indicates phytochemical screening of Drumstick (Moringa oleifera) leaf extract. Drumstick (Moringa oleifera) leaf extracts in ethanol as well as distilled water contained tannins poorly but phenolic compounds were absent, alkonoids and saponins were poorly present while flavonoids and terpenoids were absent.
Table 4 shows presence of phytochemical in Babul (Acacia nilotica) leaf extract. In ethanol and distilled water extracts of Babul (Acacia nilotica) leaf, tannins and phenolic compounds were significantly present. Extract in distilled water showed flavonoids significantly but ethanol extract contained flavonoids poorly. Alkonoids were poorly present in water extract and absent in ethanol extract. In both the extracts terpenoids poorly present while saponins were absent.

Table 5 exhibits phytochemical contents of Periwinkle (Catharanthus roseus) leaf extract. Both distilled water and ethanol extracts of periwinkle leaf contained tannins and 
phenolic compounds significantly, alkonoids, saponins and terpenoids poorly while flavonoids were absent.

Table 6 showed Total Phenolic Content of leaf extracts in distilled water and ethanol. Highest phenolic content was found in Amla leaf extract in ethanol i.e. $156.79 \mathrm{mg} / \mathrm{g}$ of dry leaf powder followed by Babul leaf extract in ethanol $(117.99 \mathrm{mg} / \mathrm{g})$. Distilled water extract of Babul leaves had TPC $106.05 \mathrm{mg} / \mathrm{g}$ and Amla leaf extract had $100.27 \mathrm{mg} / \mathrm{g}$.

Total Phenolic Content of Drumstick, Lemon and Periwinkle leaf extracts obtained using ethanol were $55.47,41.82$ and $33.85 \mathrm{mg} / \mathrm{g}$ of material respectively while TPC of the extracts of them taken out in distilled water were $27.29,19.75$ and $18.93 \mathrm{mg} / \mathrm{g}$ of dry weight respectively. It is observed that Total Phenolic Content of the leaf extract taken out in ethanol was more than the TPC of the respective leaf extracts taken out in distilled water.

In conclusion the extracts of leaves of all the selected plants contained tannins and phenolic compounds significantly. Flavonoids were poorly present in Amla leaf extract and significantly present in Babul leaf extract. Alkaloids and saponin were poorly present in all extracts except moderate presence in Amla leaf extract. Terpenoids were totally absent in all except Babul leaf extract. Ethanol extracts of Amla leaf extract exhibited the highest Total Phenolic Content i.e. $156.79 \mathrm{mg} / \mathrm{g}$ of dry material followed by Babul leaf extract $117.99 \mathrm{mg} / \mathrm{g}$.

Among distilled water extracts Babul leaf extract exhibited highest i.e. $106.05 \mathrm{mg} / \mathrm{g}$ followed by Amla leaf extract i.e. 100.27 $\mathrm{mg} / \mathrm{g}$. Total Phenolic Content of the leaf extract taken out in ethanol was more than the TPC of the respective leaf extract taken out in distilled water.

\section{Acknowledgement}

The authors would like to thank ICAR, New Delhi for providing financial assistance under All India Coordinated Research Project on Home Science through ICAR-CIWA, Bhubaneshwar for conducting the research.

\section{References}

Akindele, A. J., O.O. Adeyemi, 2007. Antiinflammatory activity of the aqueous leaf extract of Byrosocarpus coccineus. Fitoterapia 78: 25-28.

AnkitaSood, ParminderKaur and Ruby Gupta, 2012. Phytochemical Screening and Antimicrobial Assay of Various Seeds Extract of Cucurbitaceae Family, International Journal of Applied Biology and Pharmaceutical Technology, 3(3): 401-409.

Chandra M. 2013. Antimicrobial Activity of Medicinal Plants against Human Pathogenic Bacteria. International Journal of Biotechnology and Bioengineering Research. 4(7): 653658.

Mallikharjuna, L.N. Rajanna, Y.N. Sitharam and G.K. Sharanbassapa, 2007, Phytochemical Studies of Strychnospotatorum L.f.- A Medicinal Plant, E-Journal of Chemistry, 4 (4): 510-518

Manikandan A, Rajendran R, Abirami M and Kongarasi K, 2016. Antimicrobial activity and phytochemical analysis of Impatiens balsamina Seed (Kaci-ttumpai) collected from Coimbatore District, Tamil Nadu, India. International Journal of Pharm. Sci. Res., 7(12): 5039-43.

P. Saranraj, S. Sivasakthi and M. S. Deepa 2016. Phytochemistry of pharmacologically important medicinal plants - A Review, International Journal Of Current Research In Chemistry And 
Pharmaceutical Sciences, 3 (11): 56-66.

Pradeep A. et al., 2014. International Journal of Biological \& Pharmaceutical Research. 2014; 5(1): 48-50.

PushpaRuwali and DikshaNegi 2019. Phytochemical analysis and evaluation of antioxidant activity of Premna latifolia Roxb.- A medicinal plant (Family: Lamiaceae), The Pharma Innovation Journal 8(5): 13-20

Selvakumar Sivagnanam, and Anoop Prakash Chandra. 2016. Preliminary phytochemical analysis of Amarathus viridis. Research Journal of Pharmaceutical, Biological and
Chemical Sciences, 7(1): 1-7.

Uhammad Gulfraz, Alia Sadiq, Hira Tariq, Muhammad Imran, Rahmatullah Qureshi and Asyia Zeenat, 2011. Phytochemical analysis and antibacterial activity of Eruca sativa seed, Pakistan Journal of Botany 43(2): 1351-1359

Vastrad J. V., Goudar G. and Byadgi S. A. 2016. Characterization of phenolic compounds in Eucalyptus globulus and Cymbopogan citratus Leaf Extract, The Bioscan. 11(4): 2153-2156.

\section{How to cite this article:}

Sunita Kale. 2020. Screening of Phytochemical Components of Leaf Extracts. Int.J.Curr.Microbiol.App.Sci. 9(09): 2394-2401. doi: https://doi.org/10.20546/ijcmas.2020.909.299 